\title{
INTEGRAÇÃO ECONÔMICA E A FLEXIBILIZAÇÃO EM FACE DAS CRISES ECONÔMICAS: TRANSFORMAÇÕES SOCIAIS E REFLEXOS NA ÓTICA LABORAL
}

\author{
ECONOMIC INTEGRATION AND FLEXIBILITY IN FACE OF ECONOMIC \\ CRISIS: SOCIAL TRANSFORMATION AND REFLECTIONS IN PERSPECTIVE \\ LABOR
}

\author{
${ }^{1}$ Guilherme Domingos de Luca \\ ${ }^{2}$ Antonio Carlos Ferreira Do Amaral
}

\section{RESUMO}

O presente estudo visa analisar a integração econômica e a flexibilização diante das crises econômicas que afetam as relações laborais. Justifica-se a presente pesquisa, ante a realidade econômica depressiva assola a sociedade nacional. O objetivo geral se baseia na análise da flexibilização como possibilidade eficaz de proteção ao emprego nos momentos de crise, analisando, especificadamente, o contexto entre a integração econômica e a flexibilização. Trata-se do estudo pautado pelo método dedutivo, cujo os procedimentos técnicos que foram adotados, prevaleceu a pesquisa bibliográfica e documental, com base, principalmente, em livros, teses, artigos, legislação e demais dados.

Palavras-chave: Crise econômica, Flexibilização, Valorização laboral, Alternativas

\begin{abstract}
This study aims to analyze the economic integration and flexibility in the face of economic crises affecting labor relations. Justified this research, compared the depressive economic realities plaguing the national society. The overall objective is based on the analysis of flexibility as an effective possibility of employment protection in times of crisis, analyzing, specifically, the context of economic integration and flexibility. It is the study guided by deductive method, which the technical procedures that were adopted, prevailed bibliographic and documentary research, based mainly on books, theses, articles, legislation and other data.
\end{abstract}

Keywords: Economic crisis, Flexibility, Labor recovery, Alternatives

\footnotetext{
${ }^{1}$ Mestre em Teoria do Direito e do Estado pelo Centro Universitário Eurípides de Marília - UNIVEM, São Paulo (Brasil). E-mail: guilherme.luca@uol.com.br

${ }^{2}$ Mestrando em Teoria do Direito e do Estado pelo Centro Universitário Eurípides de Marília - UNIVEM, São Paulo (Brasil). E-mail: antonioamaral@globo.com
} 


\section{INTRODUÇÃO}

Ao longo dos anos, as crises econômicas impactaram diretamente no Direito do Trabalho, dada até mesmo em razão da ausência de um emprego estável e do crescimento especializado nas atividades, que poderiam ser desempenhadas pelo trabalhador, o que contribuiu para uma mudança organizacional da estrutura das relações de trabalho. Além disso, o aumento do índice de desemprego sinalizava, nesse período, que a crise era real e que afetava todas as esferas sociais.

Se não bastasse o fenômeno da globalização, sem dúvida alguma, tem íntima relação com o Direito do Trabalho, sendo que, a partir da sua ocorrência, outros fenômenos secundários também se desencadearam, tais como a privatização e terceirização.

Em relação à globalização, é possível perceber que a ideia de unicidade e soberania do Estado é deixada de lado, muito embora respeitada, trazendo uma nova forma de competição econômica internacional, em que o seu alcance é considerado irreversível, e os efeitos não acontecem de modo igualitário entre os países envolvidos, impondo ao mundo uma nova abordagem aos conceitos e reflexos. Ela tem relação direta com o modelo existente no mundo atual que se fundamenta na ideia de diminuição do tamanho do Estado e a ordem de privatização.

A partir de tais considerações, há quem considera não haver uma crise valorativa do Direito do Trabalho, em que os direitos laborais no âmbito social não podem ser vinculados aos direitos econômicos, visto que a flexibilização se apresenta como instrumento capaz de regular as questões jurídicas ali expostas.

A flexibilização visa ajustar e afastar a rigidez das normas trabalhistas ante a globalização econômica e o mundo atual, justificando essa necessidade em decorrência das crises econômicas que assolam toda a sociedade, contribuindo, consequentemente, com o aumento da produtividade e também do lucro.

Muito embora a flexibilização tenha sido tema de debate de diversos outros artigos, a temática se apresenta e justifica-se de forma absolutamente relevante no atual contexto social, em que notoriamente, uma crise econômica assola a sociedade nacional. Diante disso, emerge-se o seguinte problema: Mesmo nos dias atuais, após inúmeras conquistas trabalhistas, a flexibilização ainda se apresenta como uma solução eficaz no que concerne a manutenção e proteção ao emprego em face das crises econômicas que impactam nas relações empresariais? 
Nesse contexto, o objetivo geral da pesquisa se baseia justamente na questão analítica acerca da flexibilização como possibilidade eficaz de proteção ao emprego nos momentos de crise, analisando, especificadamente, o contexto entre a integração econômica e a flexibilização.

Segundo as bases lógicas de investigação, trata-se de pesquisa desenvolvida pelo método dedutivo, cujos procedimentos técnicos que foram adotados, prevaleceu a pesquisa bibliográfica e documental, com base, principalmente, em livros, teses, artigos, legislação e demais dados.

\section{TRANSFORMAÇÕES SOCIAIS E O IMPACTO NO DIREITO DO TRABALHO}

Os anos compreendidos entre a década de 1940 e meados de 1975 foram essenciais para a positivação das normas laborais no Brasil, destacando, inclusive, a aprovação da CLT e posteriormente a promulgação da Constituição de 1988.

Doravante, após esse período de grandes conquistas laborais, a sociedade deflagrouse em crise econômica por causa dos inúmeros fatos ocorridos no Brasil e no mundo, como por exemplo, a crise petrolífera de 1973. "Era natural que o Direito do Trabalho se ressentisse da crise econômica provocada pela queda do petróleo, já que está atrelado à economia" (CAVALCANTI, 2008, p. 81).

A década de 1970 foi um marco para as grandes crises em razão das taxas de lucro decorrente do aumento da força de trabalho, durante os períodos de pós-guerra, e da incapacidade de modelo de acumulação de produção e consequente desemprego, da crise do bem-estar social, da concentração de capital e das privatizações (ANTUNES, 1999, p. 29). Falava-se em uma nova reconfiguração do capitalismo:

A dinâmica de mundialização e financeirização da economia e dos mercados insere-se num amplo movimento de reconfiguração do capitalismo, ancorado pela grande indústria transnacional em estreita associação com o mundo das finanças e com os interesses do capital rentista (DEGENSZAJN, 2013, p. 612).

Essas crises econômicas desencadearam uma perda de lucratividade das empresas, dado o excesso de capacidade da produção fabril, que evidentemente, estimulou a transferência do capital para as finanças. Por conseguinte, esse fato justificou a baixa no rescimento da produção e dos salários, o que evidenciou a necessidade de reorganização do capital das empresas e até mesmo do seu sistema político organizacional. 
Esta referida crise econômica impactou diretamente no Direito do Trabalho, em razão da ausência de emprego estável e do crescimento especializado nas atividades que poderiam ser desempenhadas pelo trabalhador, o que contribuiu para uma mudança organizacional da estrutura das relações de trabalho. Se não bastasse, o aumento do índice de desemprego sinalizava nesse período que a crise era real e que afetava todas as esferas sociais.

Além disso, muitas indústrias passaram a substituir o seu capital humano pela automatização do seu processo produtivo, atreladas a ideia do pensamento neoliberal provocado pelo Estado, que pregava a necessidade de reestruturação no sistema capitalista "com predominância do capital financeiro e dos investimentos especulativos em detrimento do capital produtivo" (CAVALCANTI, 2008, p. 88).

Ante a reestruturação industrial, as demissões em massa tornaram-se uma realidade comum, em que muitas empresas de pequeno e médio porte surgiram no mercado, visando a atender a demanda dos serviços decentralizados das grandes empresas, o que seria uma atividade meio em relação ao que era desempenhada no ciclo produtivo industrial, uma espécie de terceirização (ANTUNES, 2005, p. 30).

Por conta das demissões ocasionadas pelo novo processo de produção e do surgimento das novas empresas de pequeno e médio porte, figurou-se um novo ciclo produtivo, em que a grande empresa era responsável por parte das contratações e a outra parte era feita pelas pequenas empresas, que, em muitos casos, contratavam os demitidos das grandes empresas, criando-se uma desigualdade que vai desde o tratamento até as questões salariais, visto que essa contratação se dá em razão de uma subcontratação cerceada de direitos laborais básicos.

Posteriormente, na década de 1980, houve uma acentuada desigualdade do trabalho qualificado e do não qualificado, atrelado à consequente distribuição de renda que não ocorria de forma equânime.

Essa acentuação das desigualdades não foi prevista pela teoria pura do comércio internacional, porque para ela o aumento do bem-estar, como consequência da especialização internacional segundo as dotações respectivas dos fatores de produção, deveria reduzir as desigualdades nos países relativamente abundantes em mão-de-obra, porque estes deveriam a partir de então importar bens que necessitam muito capitais e incorporam, sobretudo trabalho qualificado e exportar bens que consomem pouco capital e incorporam sobretudo trabalho não-qualificado (SALAMA, 1999, p. 32).

Diante das crises, o trabalho informal ou economia informal se tornou uma realidade em todo o mundo. "Existe uma compreensão amplamente difundida de que se tornou um 
fenômeno expressivo nos países subdesenvolvidos ou em transição e que começa a aparecer nos países centrais" (KREIN; WEISHAUPT PRONI, 2010, p. 33).

Nesse período, os recursos econômicos deixaram também de ser considerados como meio de produção. O conhecimento se tornou o elemento essencial:

\begin{abstract}
Agora o valor é criado pela "produtividade" e "inovação", qualquer delas aplicações do conhecimento no trabalho. Os grupos sociais líderes da sociedade do conhecimento serão os "trabalhadores do conhecimento" executivos do conhecimento que sabem como alocar o conhecimento para uso produtivo, tal como os capitalistas alocavam o capital para uso produtivo - ou seja, os profissionais do conhecimento, os empregados do conhecimento. Praticamente toda esta gente do conhecimento será empregue nas organizações. (...) O desafio econômico da sociedade pós-capitalista será a produtividade do trabalho e do trabalhador com base no conhecimento (DRUCKER, 1993, p. 21-22)
\end{abstract}

Posterior a tais ocorrências, surge uma nova era em razão das transformações significativas da sociedade. Essa era ocorre a partir do momento em que a tecnologia da informação surge e, com ela, um novo tipo de trabalho: o do conhecimento.

Nessa nova era, houve uma nova reestruturação e organização nas relações de trabalho, em que há "homens e mulheres cujos conhecimentos e ideias abastecem a sociedade da informação de alta tecnologia" (RIFKIN, 1996, p. 187). A revolução tecnológica trouxe um novo mercado de trabalho, destinado a uma elite de trabalhadores possuidores de habilidades e técnicas intelectuais da economia.

Todavia, antes de adentrar-se nas questões valorativas do Direito do Trabalho, cumpre demonstrar, ainda, o impacto da globalização e consequentes efeitos no cenário jurídico objetivo.

\title{
2 IMPACTO DO FENÔMENO DA GLOBALIZAÇÃO NO MUNDO ATUAL
}

O fenômeno da globalização, sem dúvida alguma, possui íntima relação com o Direito do Trabalho. A partir da sua ocorrência, outros fenômenos secundários também se desencadearam, tais como a privatização e terceirização.

O capitalismo se propagou no mundo junto com a globalização, que, ao contrário do que muitas pessoas afirmam, não é um fenômeno novo, uma vez que também ocorreu no final do século XV.

Nos últimos anos, a partir da década de 1980, conforme já mencionado, o mundo passou por inúmeras modificações em razão das crises que assolaram as mais diversas 
economias, tais como o Brasil. Seja no campo geográfico, como também na economia ou política, houve um evidente enfraquecimento dos países ricos e a miserabilidade acentuada dos países tidos como mais pobres.

O novo da era global é que se perdeu o nexo entre a pobreza e a riqueza, e isto é, segundo Bauman, a causa da globalização que divide a população mundial em riscos globalizados, que dominam o espaço e têm tempo, e pobres localizados, que estão presos ao espaço e têm que matar o tempo, com o qual não têm nada para fazer (BECK, 2004, p. 90-91) ${ }^{1}$.

Na globalização, é possível perceber que a ideia de unicidade e soberania do Estado é deixada de lado, embora seja respeitada. As relações transbordam os limites e fronteiras físicas, tendo em vista que a livre circulação de capital é altamente difundida por toda a sociedade, além do impacto nas relações econômicas, políticas, sociais, ambientais e até culturais (VIEIRA, 1998, p. 72), integrando-se a esfera nacional.

No fenômeno da globalização, as relações empresariais ultrapassam quaisquer limites territoriais que possam existir, uma vez que a internacionalização é uma característica absolutamente marcante.

A globalização, no que diz respeito ao impacto econômico, está associada a diversos fatores, tais como a revolução tecnológica, a adoção de políticas econômicas influenciadas pela ideologia neoliberal, grau de liberdade na movimentação do capital, ampliação do fluxo de comércio e informações, atuação das empresas transnacionais, dentre outros.

Ante a livre circulação de bens e valores que ocorreram a partir do fenômeno da globalização, há inúmeras críticas de favorecimento aos crimes de evasão de divisas ${ }^{2}$ e também de lavagem de dinheiro, obtido por meios ilícitos. Tal fato corrobora até mesmo com o tráfico internacional de substâncias entorpecentes e armas (GOLDSCHMIDT, 2009, p. 119).

A globalização trouxe uma nova forma de competição econômica internacional, em que o seu alcance é considerado irreversível. Seus efeitos não acontecem de modo igualitário entre os países envolvidos, dado que há uma imposição ao mundo uma nova abordagem aos conceitos e reflexos.

\footnotetext{
${ }^{1}$ No original: Lo nuevo de la era global es que se há perdido el nexo entre pobreza y riqueza, y esto es, según Bauman, a causa de la globalización que divide a la población mundial em ricos globalizados, que dominan el espacio y no tienen tempo, y pobres localizados, que están pegados al espacio y tienen que matar su tienpo, com el que no tienen nada que hacer.

${ }^{2}$ A evasão de divisas diz respeito ao crime financeiro do qual se envia divisas para o exterior de um país sem declará-lo à repartição federal competente. Ele também é denominado como evasão cambial.
} 
No que diz respeito ao lado político da globalização, este fenômeno conseguiu restaurar a separação da economia do domínio político, em que os governantes passaram a se defrontar com uma capacidade de regulamentação e controle diminuído. Eles são, portanto, meros administradores do ajuste da economia, cujo objetivo é ganhar competitividade no mercado global e assegurar confiança hábil em atrair os investidores.

No âmbito social, as mudanças decorrentes do fenômeno da globalização ocasionaram em inúmeras formas de exclusão social e, consequentemente, impactou toda a proteção do Direito do Trabalho.

A globalização ocasionou uma destruição impensada dos recursos naturais, principalmente os não renováveis. Alguns autores criticam a globalização em razão da sua impulsão ao abuso dos recursos naturais impensadamente e exageradamente:

(...) é, realmente, de extrema arrogância e brutalidade com a natureza e quaisquer outros modelos que não seja esse, de apropriação, de lucro e de acumulação. Sua base é um antropocentrismo intolerante que desqualifica a priori todos os demais seres - reputados simples meios ou coisas - objetos inferiores, à disposição do rei da criação. $\mathrm{O}$ paradoxo desse fundamentalismo econômico, é que a desqualificação é do próprio homem, que se avilta na pobreza, em mazelas sociais e risco de extinção como espécie, pelo esgotamento acelerado do planeta (PILATI, 2006, p. 11).

Associada à globalização, o consumismo se fez absolutamente presente na sociedade, adquirindo uma condição de "status social". Isso se deve ao fato de a sociedade necessitar da produção, independentemente de uma análise preventiva se a sua atitude pode ou não colaborar com a degradação ambiental e com a consequente perda de qualidade de vida dos seus pares. Em relação à cultura, houve uma padronização dos costumes e conceitos advindos, principalmente, dos moldes norte-americanos (GOLDSCHMIDT, 2009, p. 121).

Tratando-se puramente da relação globalização x Direito do Trabalho, houve grande impacto nos direitos sociais, por casa de uma denominada crise normativa que foi obrigada a agir de forma pluralmente protecionista ao trabalhador. A globalização tem relação direta com o modelo neoliberal, que se fundamenta na ideia de diminuição do tamanho do Estado e a ordem de privatização inserida no contexto como todo.

(...) o termo globalização tem sua origem na literatura destinada às firmas multinacionais, designando inicialmente um fenômeno limitado a uma mundialização da demanda se enriquecendo com o tempo até o ponto de ser identificada atualmente a uma nova fase da economia mundial $\begin{array}{llll}\text { (MAGALHÃES, 2000, } & \text { p. }\end{array}$ 
Ocorre que, ante as ocorrências de crises, já abordadas, a partir da década de 1970, a política e ideal neoliberal foram aplicadas com o intuito de se assegurar a cumulação de capital, que até então estava em guerra.

O neoliberalismo se baseia no conjunto de ideias políticas e econômicas, advindas do capitalismo, que defende a não participação do Estado na economia, havendo ampla liberdade do comércio, responsável por um determinado crescimento econômico. Dentre os seus ideais, destacam-se:

\begin{abstract}
Nesse sentido, o neoliberalismo defende um Estado minimizado em relação aos direitos sociais e trabalhistas e, ao mesmo tempo, passivo em relação aos lucros dos capitalistas e aos interesses do mercado. Preconiza liberdade de movimentos para todos, menos leis, mais espaço para a economia desenvolver-se livremente, mesmo desprezando políticas públicas estatais. Está, enfim, atrelado a essa nova fase do capitalismo internacional que orienta a formação de centros econômicos em regiões, a derrubada de fronteiras comerciais, a livre circulação do capital e o fortalecimento de conglomerados transnacionais (CAMPANA, 2000, p. 134).
\end{abstract}

Segundo os ideais neoliberais, o Estado deveria parar de intervir no mercado, bem como defender os Direitos Sociais. Isso, nos dias de hoje, seria ilógicos, tendo em vista os inúmeros direitos constitucionais amplamente consagrados na Constituição.

No sentido contrário aos ideários neoliberais, posicionam-se aqueles que defendem a intervenção do Estado no mercado de trabalho, dada a necessidade da manutenção dos sistemas de proteção social por meio de uma legislação própria, no meio político e econômico desfavorável, no caso dos países subdesenvolvidos.

De fato, todo o fenômeno da globalização, atrelado ao neoliberalismo e a não participação do Estado na economia, trouxe significativas mudanças no direito laboral, bem como impactou o contrato de trabalho. Ressalta-se que o que incide nas privatizações, terceirizações, desregulamentação e flexibilização (CATHARINO, 1997, p. 49).

Dentre as transformações advindas da globalização e o seu impacto no mundo atual, a privatização e as terceirizações, fenômenos jurídicos herdados do impacto da globalização e do neoliberalismo nas relações jurídicas trabalhistas.

A globalização também é responsável pelo afastamento do Estado na proteção da relação de emprego, desconstruindo, inclusive, a aplicação do princípio da proteção, que conforme já estudado, tem o objetivo de reduzir a desigualdade existente na relação empregado 
O neoliberalismo trouxe à tona a necessidade de o Estado ser mínimo, tanto no que diz respeito à regulação e proteção do trabalho, quanto no que diz respeito à intervenção na economia. Ante a ideia de intervenção mínima do Estado, a partir dos conceitos neoliberais, pondera-se o pensamento de redução dos atos originados do Poder Executivo na economia, que só estaria legitimado para atuar como agente regulador e fiscalizador na sociedade em funções fiscalizadoras e de planejamento.

É importante ressaltar que toda essa relação histórica que desencadeou a globalização, os ideais neoliberais e, consequentemente, as privatizações e a terceirização apontam para uma possibilidade de crise valorativa do Direito do Trabalho.

\section{DIREITO DO TRABALHO E A CRISE VALORATIVA NA SUA POSITIVAÇÃO}

Ao longo da história, as relações entre empregador e empregados são marcadas por inúmeros conflitos decorrentes puramente do interesse econômico, prevalecido pelo detentor do poder diretivo econômico em face do empregado em situação desfavorecida. Entretanto, tal afirmativa não é regra na ótica laboral, visto que os conflitos muitas vezes exprimem a crise valorativa sofrida pelo Direito do Trabalho.

Tratando da realidade social existente no Brasil e no mundo, desde o final do século passado, atrelado à existência da Constituição de 1988, as ocorrências de profundas transformações capitalistas desencadearam a normatização trabalhista a uma crise valorativa.

Por outro lado, há quem considera não haver uma crise valorativa do Direito do Trabalho, de modo que os direitos laborais no âmbito social não podem ser vinculados aos direitos econômicos:

A crise está relacionada à situação de conflito que impacta nas relações sociais e também na organização social, sendo meramente complexo atribuir a sua causa, no contexto econômico, exclusivamente a positivação trabalhista. Além disso, as normas trabalhistas foram criadas com a intenção meramente protecionista ao trabalhador e a sociedade de modo natural, em que o Estado atua como agente pacificador de Direito.

Ante as transformações decorrentes da globalização e do pensamento neoliberal, muitos pesquisadores afirmam a necessidade de reestruturação da economia, o que afetaria, consequentemente, a proteção social que abrange o Direito do Trabalho. 
A afirmativa da redução da necessidade do "trabalho vivo" traz, porém, no seu bojo uma verdade: uma radical transformação do mundo do trabalho e uma crescente desestruturação das comunidades operárias clássicas. Mas o neoliberalismo e a reestruturação produtiva não apontaram para a abolição nem o rechaço do trabalho, senão para a polarização, a precarização, o desemprego estrutural, a marginalização dos sindicatos e o surgimento de novos movimentos sociais cujas demandas não passaram pelo não-trabalho (GENRO, 2002, p. 27).

É possível perceber que o Direito do Trabalho é acusado pelo neoliberalismo por todos os males atuais na sociedade no que diz respeito aos problemas econômicos. O elevado índice de norma jurídica atrelada à responsabilização dos empregadores inibe a modernização do processo produtivo, assim como inibe os investimentos, sacrificando cada vez mais os desempregados e jovens que almejam recolocação ou colocação no mercado de trabalho.

Nessa perspectiva de crise valorativa, o Direito do Trabalho tem sido apontado como o grande vilão do avanço econômico e superação da crise social pelo fato de ter sido acusado de "ter feito excessivas concessões aos trabalhadores, impedindo ou dificultando medidas de adequadas à superação da crise" (LEITE, 1990, p. 24).

Dentre as medidas positivadas no ordenamento jurídico, que são criticadas em razão do impacto econômico no capitalismo, está, por exemplo: a) a fixação de jornada de trabalho, que passou a ser limitada, possibilitando o pagamento de adicional, em caso de inobservância; b) a fixação de salário mínimo ou de piso normativo, conforme a categoria; c) a elasticidade dos períodos de repouso e descanso do trabalhador, tanto no período semanal como no anual; d) a inserção dos sindicatos nas empresas e maior participação e segurança jurídica dos trabalhadores; e e) a dificuldade cada vez maior da funcionalidade da mão-de-obra.

À margem do pensamento crítico ao Direito do Trabalho, urge que a natureza tutelar laboral contribui para a real crise, o que impede medidas adequadas de superação. Segundo o pensamento neoliberal, a medida mais evidente de superação da crise ocorre a partir da flexibilização, inserindo-se na sociedade uma diminuição dos riscos do capital em face da solidez do emprego, de modo que o empregado também assuma o risco em benefício do capital.

A partir da ideia neoliberal atrelada ao fenômeno da globalização, afirmam que as conquistas advindas na legislação trabalhista foram adquiridas em momentos oportunos, cuja finalidade era de atender as reivindicações dos trabalhadores em determinados períodos, não podendo ser aplicado em situações de conjuntura depressiva da economia. 
Por outro lado, há quem defenda a teoria de que os direitos trabalhistas só serão alterados caso haja persistência da crise, adotando-se, então, medidas permanentes. Alguns critérios podem ser utilizados na aferição da existência ou não de crise no Direito do Trabalho, tais como o critério da contradição entre a norma e a realidade social, a inefetividade do direito laboral e/ou seu desvio de finalidade, a sua absorção e abrangência em outros ramos do direito e a sua importância e relação no desenvolvimento econômico (XAVIER, 1990, p. 132).

A concepção de Direito do Trabalho se aplica nas relações jurídicas de forma ampla e complexa, uma vez que não se trata apenas de relação entre empregado, empregador e leis, mas sim de um conglomerado de rede de normas e situações capazes de abranger todos os princípios, regras e instituições atinentes a relação empregatícia. Essa concepção é orientada pela CLT, Constituição Federal e legislação extravagante que possa existir cujos efeitos produzem repercussão em toda a sociedade.

Ademais, o Direito do Trabalho traz consigo importantes funções, como a promoção da justiça social, mesmo que de forma genérica, distribuindo aos trabalhadores determinados ganhos econômicos elevando e modernizando a economia e a sociedade, bem como trazendo um ideal democrático e civilizatório.

Partindo-se do pressuposto neoliberal, a flexibilização ainda se mostra como alternativa essencial na arrumação e ajustes da economia, corrigindo as denominadas imperfeições do mercado.

Ante a sua relevância jurídica e polêmica que traz no contexto social, é importante estudar minuciosamente seu instituto e efeitos originados na legislação trabalhista brasileira vigente.

\section{DA FLEXIBILIZAÇÃO DAS NORMAS TRABALHISTAS COMO SOLUÇÃO SOCIAL DIANTE DAS CRISES E SUA LIMITAÇÃO CONSTITUCIONAL}

Muitas são as definições atribuídas à flexibilização do direito trabalhista, sendo a temática absolutamente complexa no cenário jurídico e social.

O termo pode ser empregado dentre diversos sentidos. Dentro de um extremo, “situam-se os que defendem 'flexibilização' como 'desregulamentação', ou seja, como retirada da norma protetora, a fim de que o sistema econômico estabeleça condições de contratação laboral” (NASSIF, 2001, p. 73). Juridicamente, está relacionada ao ajuste exigido 
pela economia, ante a postergação dos direitos dos trabalhadores, como meio de desenvolvimento contra a absorção.

A flexibilização visa a ajustar e a afastar a rigidez das normas trabalhistas diante da globalização econômica e do neoliberalismo, justificando essa necessidade em decorrência das crises econômicas que assolam toda a sociedade, contribuindo, consequentemente, com o aumento da produtividade e também do lucro. Essa denominação busca "dar maior elasticidade às regras trabalhistas, em contrapartida àquela fixação rígida que sempre se preconizou. Seria uma nova forma de enfrentar as crises econômicas" (MARTINS, 2015, p. 09).

\begin{abstract}
Admite para dar conteúdo jurídico "a esta ideia", valer-se da opinião de autores espanhóis que consideram ser a "flexibilidade", basicamente, capacidade de adaptação do regime normativo e do das instituições à vontade unilateral ou bilateral das partes da relação de trabalho. Mais ainda, considera que a flexibilidade significa fundamentalmente adequação da normativa laboral e concomitantemente uma diversificação dos níveis de proteção que brinda a seguridade social (CATHARINO, 1997, p. 49).
\end{abstract}

A flexibilização se fundamenta no sentido de que a legislação trabalhista deve se manter maleável em razão da rigidez legal dos direitos sociais, sendo uma reação aos padrões até então vigentes da legislação, os quais estão em desacordo com a realidade.

No cenário internacional, a flexibilização é vista como a "capacidade de os indivíduos na economia e em particular no mercado de trabalho de renunciar a seus costumes e de adaptar-se a novas circunstâncias" (ORGANIZAÇÃO DE COOPERAÇÃO E DE DESENVOLVIMENTO ECONÔMICO, 1986, p. 06).

Esse fenômeno também consiste na adoção de medidas e de procedimentos, cuja natureza jurídica tem a finalidade de atender a esfera social e econômica, assegurando e promovendo a possibilidade de ajuste na produção, no emprego e nas condições de trabalho.

É o instrumento de política social caracterizado pela adaptação constante das normas jurídicas à realidade econômica, social e institucional, mediante intensa participação de trabalhadores e empresários, para eficaz regulação do mercado de trabalho, tendo como objetivos o desenvolvimento econômico e o progresso social (HOYOS, 1990, p. 378).

Há quem considera que a flexibilização surge como uma solução para a crise mundial, impactando, inclusive, no Direito nacional. 
É no argumento da busca por soluções para a crise mundial que surge a discussão em torno da flexibilização do Direito do Trabalho. Também no Brasil, onde as dificuldades econômicas não decorrem apenas do processo de globalização da economia, mas também são conjunturais, a controvérsia a respeito da implementação de um novo sistema de equilíbrio das forças do capital e do trabalho ainda é a mais acentuada (SÁVIO, 1997, p. 593).

A flexibilização envolve uma série de aspectos, compreendendo desde fatores econômicos, como também políticos e sociais. Na sociologia, a flexibilização trabalhista está ligada à capacidade de renúncia a determinados costumes e de adaptações a novas situações. $\mathrm{Na}$ ideia jurídica, a flexibilização é o "conjunto de regras que tem por objetivo instituir mecanismos tendentes a compatibilizar as mudanças de ordem econômica, tecnológica, política ou social existente na relação entre o capital e o trabalho" (MARTINS, 2015, p. 13).

Ela representa a atenuação rígida do Direito do Trabalho, assegurando a aplicação de medidas menos favoráveis do que as previstas em lei, ante uma negociação prévia, conforme a seguir:

(...) a flexibilização representa a atenuação da rigidez protetiva do Direito do Trabalho, com a adoção de condições trabalhistas menos favoráveis do que as previstas em lei, mediante negociação coletiva, em que a perda de vantagens econômicas poderá ser compensada pela instituição de outros benefícios, de cunho social, que não onerarão excessivamente a empresa, nos períodos de crise econômica e transformações na realidade produtiva (MARTINS FILHO, 1998, p. 09).

A flexibilização do Direito do Trabalho se baseia em um conjunto, em razão de compor um todo organizado, uma sistemática que visa a compatibilizar as regras de Direito do Trabalho com as mudanças, conforme já dito, visando, especialmente, a tornar menos rígida as relações trabalhistas. Inegavelmente está relacionada ao oposto de rigidez, visto que sua ideia literalmente evoca algo que é flexível, elástico. Na prática, seria o mesmo que substituir uma norma pela outra mais flexível ou uma Convenção Coletiva que assume o papel de norma.

O instituto da flexibilização ou da flexibilidade das normas trabalhistas diz respeito, nos dias atuais, a uma postura do legislador de permitir que as relações entre os empregados e empregadores ocorram de formas equacionadas, diversas da prevista no contrato de trabalho, de modo que qualquer problema originado no transcurso da vigência contratual possa ser solucionado em regras diversas das estipuladas na CLT.

Com isso, conforme já destacado, a norma trabalhista deixa de ser rígida e passa a adotar medidas e condições de trabalho menos favoráveis do que as previstas em lei, mediante 
uma negociação prévia ou coletiva. A perda de vantagens pode ser compensada pela inserção de outros benefícios de cunho social, por exemplo, mas que não onerará excessivamente a empresa, que, em via de regra, está em crise ou em transformação na sua realidade produtiva (MANUS, 2002, p. 126).

O fenômeno da flexibilização não diz respeito puramente à quebra de rigidez da norma jurídica, mas sim a de condições de trabalho e regras que serão observadas e aplicadas em relação ao contrato de trabalho.

Portanto, não se fala em revogação ou exclusão de direitos, mas sim na modificação de certos direitos mediante negociação coletiva, notadamente em razão das crises econômicas existentes. Dentre as diversas e mais variadas definições acerca deste instituto, percebe-se claramente a divergência entre o capital e o trabalho, ante o impacto da economia sobre o direito em decorrência da globalização.

Há relatos de que a flexibilização do Direito do Trabalho no Brasil nasceu na década de 1990, momento em que o Brasil passava por importantes mudanças, redefinindo a sua própria formação social, bem como uma reestruturação produtiva do capital, adoção de receituário da acumulação flexível, intensificação do denominado lean production ${ }^{3}$ e disseminação das formas de subcontratações e terceirizações das forças de trabalho (CAVALCANTI, 2008, p. 171).

Nesse período histórico, inúmeros acontecimentos contribuíram com a ideia de flexibilização no Direito Brasileiro, visto que ocorreram privatizações de setores estratégicos da economia brasileira, marcadas por políticas tidas como neoliberais, pelo então Presidente Fernando Henrique Cardoso.

Mas, antes mesmo deste fato histórico da década de 1990, a flexibilização já se fazia presente no ordenamento jurídico brasileiro, de modo que muitas leis facultavam direitos dos trabalhadores, tais como a lei $\mathrm{n}^{\circ} 6.019$, de 1974, que facultou o funcionamento de empresa de trabalho temporário, bem como a Lei $\mathrm{n}^{\circ} .7 .102$, de 1983, que possibilitou a terceirização dos serviços de segurança nos estabelecimentos financeiros.

\footnotetext{
${ }^{3}$ Relaciona-se a ideia manufatura enxuta ou manufatura esbelta, sendo também chamada de Sistema Toyota de Produção. Diz respeito a uma filosofia de gestão focada na redução dos sete tipos de desperdícios (superprodução, tempo de espera, transporte, excesso de processamento, inventário, movimento e defeitos).

${ }^{4}$ A empresa que, em face da conjuntura econômica, devidamente comprovada, se encontrar em condições que recomendem, transitoriamente, a redução da jornada normal ou do número de dias do trabalho, poderá fazê- lo, mediante prévio acordo com a entidade sindical representativa de seus empregos, homologada pela Delegacia Regional do Trabalho, por prazo certo, não excedente de 3 (três) meses, prorrogável, nas mesmas condições, de ainda indispensável, e sempre de modo que a redução do salário mensal resultante não seja superior a 25\% (vinte e cinco por cento) do salário contratual, respeitado o salário mínimo regional, e reduzidas proporcionalmente a $\begin{array}{llllll}\text { remuneração } & \text { a } & \text { gratificações } & \text { gerentes } & \text { diretores. }\end{array}$
} 
Fala-se, inclusive, da existência da flexibilização "heterônoma", regulada pela Lei $\mathrm{n}^{\circ}$ 4.923, de 23 de Dezembro de $1965^{4}$, que fortaleceu as negociações coletivas, que posteriormente foram consagradas na redação da atual Constituição Federal, em que o negociado prevaleceria sobre as disposições relativas às questões salariais e de jornada.

A flexibilização se faz presente em razão de inúmeros mecanismos que podem ser aplicados na legislação brasileira, tais como a flexibilidade de remuneração, a utilização de força de trabalho e a relação de estabilidade no tempo e duração do contrato de trabalho (BARROS, 1997, p. 271).

Por outro lado, há quem pondera que a normatização trabalhista, destacando a CLT, apresenta-se de forma tão rígida que a ausência de flexibilização contribui inclusive para o fenômeno da informalidade: "Pior ainda é a situação dos que se encontram na informalidade, sem qualquer tipo de garantia, alheios aos direitos trabalhistas e previdenciários, em virtude da falta de flexibilidade da CLT" (SOUZA, 2004, p. 185).

Em 1967, o contrato por prazo determinado, que claramente se apresenta como forma de flexibilização, já se fazia presente, assim como, em 1974 foi regulada a questão dos trabalhadores temporários terceirizados e, em 1983, a terceirização dos vigilantes.

Ademais, a liberdade de dispensa do empregado imotivadamente e a criação do FGTS na década de 1990 foram medidas de flexibilização, tal como a quebra do princípio da irredutibilidade salarial e flexibilização da jornada de trabalho, inseridas, inclusive na norma Constitucional.

A ampliação da jornada mediante negociação coletiva em turnos ininterruptos de revezamento, os contratos por prazo determinado, visando s estimular a criação de empregos, a ampliação da hipótese de terceirização, à adesão ao programa de alimentação do trabalhador, a redução de salário utilidade, a integralização de gorjetas ao salário, dentre outras medidas acima apontadas, evidenciam-se como claro flexibilizador do legislador na aplicação da norma trabalhistas no Brasil.

(...) o sistema brasileiro de relações do trabalho tem, simultaneamente, um componente de rigidez e outro de flexibilização. A rigidez vem dispositivos constitucionais, legais e judiciais. A flexibilidade vem da possibilidade de renovação periódica de acordos e convenções (PASTORE, 1995, p. 190).

Há quem defenda que o sistema jurídico nacional necessita de um programa de reforma trabalhista, capaz de superar a legislação atual que se mostra defasada. Diante desse levantamento apresentado e existente no ordenamento jurídico brasileiro acerca da 
flexibilização, é imperioso destacar tal temática em face da Constituição Federal de 1988, que veementemente acirrou os debates, tendo em vista que permitiu diversas

modificações nos direitos trabalhistas até então existentes, mediante negociações, que foi um marco normativo acerca da flexibilização no Brasil. Por outro lado, "quanto à constitucionalização dos direitos do trabalho, foi possível perceber que a Carta Magna visa à promoção e respeito da dignidade do homem (LUCA; POZZOLI, 2015, p. 105)".

Embora seja considerada rígida, ela trouxe significativos dispositivos que possibilitaram a flexibilização laboral. Aponta-se, inclusive, para a adoção de linhas básicas pela redação constitucional brasileira:

As linhas básicas adotadas pela Constituição Federal são as seguintes: 1) adoção de um modelo prescritivo, não omisso, segundo a diretriz do constitucionalismo social e seus objetivos fundamentais, que compreendem a ideia da inclusão de direitos sociais nas Constituições. 2) opção por um texto constitucional não sintético, de certo modo extenso e que, apesar de poucos artigos, contém inúmeros incisos dispondo sobre uma variedade de direitos trabalhistas, em dimensão, até hoje, desconhecida de nossas Constituições; e 3) inclusão, na Constituição, de novos direitos trabalhistas, assim considerados aqueles até agora não previstos em nossa ordem jurídica, como também aqueles que o eram apenas em nível de legislação ordinária, passando, com a Constituição a nível maior (NASCIMENTO, 2001, p. 14261427).

Os mecanismos de flexibilização são reais na Constituição Federal, de modo que a Carta Magna iniciou um processo de modernização do Direito do Trabalho brasileiro, visando a afastar a tutela do Estado e a abrir margens de entendimento entre empregados e empregadores. Dentre essas alterações, destacam-se a negociação coletiva e o acordo coletivo, tendo esses as funções de alterar em benefício ou não ao trabalhador.

Ademais, alguns autores denotam que a flexibilização à luz da redação Constitucional ocorre em determinadas oportunidades, tais como o inciso VI, XIII e XIV, do artigo $7^{\circ}$, da Constituição Federal.

No tocante a irredutibilidade salarial, a doutrina se posiciona no sentido de que o inciso IV, do artigo $7^{\circ}$, deve respeitar a garantia do trabalhador ao salário mínimo.

Quanto à possibilidade de flexibilização da jornada de trabalho, a Constituição Federal se manifesta no sentido de que a jornada não será superior a oito horas diárias ou quarenta e quatro semanais, facultando-se a compensação dos horários e redução da jornada, mediante convenção coletiva. Em relação ao regime de compensação da jornada de trabalho, 
ela traz a possibilidade de prorrogação da jornada, sem o pagamento de horas extras, de modo que as horas excedentes das normais prestadas serão deduzidas em outra oportunidade.

Quanto aos poderes atribuídos aos sindicatos, ressalta-se que a flexibilização trazida pela Constituição Federal possui um viés absolutamente negocial, razão pela qual os sindicatos passaram a ter importante papel na normatização trabalhista como, por exemplo, negociar piso salarial, jornada de trabalho, dentre outros.

Outro ponto que merece destaque em relação à flexibilização e a Constituição Federal está relacionado à Emenda Constitucional n ${ }^{\circ} 28$ de Maio de 2000, que alterou o artigo $7^{\circ}$, inciso $\mathrm{XXIX}^{5}$, da Constituição Federal, em que a ação quanto aos créditos trabalhistas proveniente das relações laborais teriam o prazo prescricional de cinco anos até o limite de dois anos após o término do contrato de trabalho, sendo as prescrições quinquenal e bienal.

A justificativa acerca da questão prescricional ocorreu a partir da necessidade de resguardo do empregador rural, visto que, em muitos casos, eles tinham que vender sua propriedade ou empenhar toda a sua economia para pagar débitos decorrentes de condenação trabalhista. A limitação acerca da flexibilização nos dias atuais recaiu ao Poder Judiciário, que tem o papel de interpretar e validar as negociações coletivas dentro dos limites e parâmetros impostos pela Constituição Federal. Por outro lado, é possível perceber que o fenômeno da flexibilização implica também em uma denominada subtração de Direito do Trabalho, embora exista uma previsão Constitucional.

No Brasil, os limites da flexibilização são dois: as normas de ordem pública, que não podem ser modificadas pelas partes, assegurando-se o mínimo ao trabalhador; e quando for contrariada, a política econômica do governo (MARTINS, 2015, p. 126).

O primeiro caso, em que as normas de ordem pública não podem ser modificadas pelas partes, está relacionado à observância mínima contida na Constituição Federal ou também nas Leis, autorizando, porém, que a norma coletiva assegure direitos superiores aos existentes na norma. Por exemplo, não seria possível estabelecer o aviso prévio em período inferior aos trinta dias, mas uma Convenção Coletiva poderia estipular o prazo de quarenta e cinco dias; assim como não seria possível se estabelecer unilateralmente o não pagamento de décimo terceiro salário ou gratificação natalina, mas poderia ser criado o décimo quarto salário em benefício do trabalhador.

\footnotetext{
${ }^{5}$ XXIX - ação, quanto aos créditos resultantes das relações de trabalho, com prazo prescricional de cinco anos para os trabalhadores urbanos e rurais, até o limite de dois anos após a extinção do contrato de trabalho; (Redação dada pela Emenda Constitucional $n^{\circ} \quad 28, \quad$ de 25/05/2000).
} 
Em relação à vedação de contrariedade da política econômica do governo, mencionase, por exemplo, o artigo 623 da CLT, que expõe a nulidade de convenção ou acordo coletivo que contrarie de forma direta ou indiretamente a proibição ou norma disciplinadora de políticas econômico-financeira do governo no que tange à política salarial vigente.

Ressalta-se a vedação da flexibilização dos direitos fundamentais do trabalhador, tendo em vista se tratar de matéria de ordem pública, não podendo ser deliberado por convenção ou acordo coletivo algum, dado seu caráter inalienável, imprescritível e indisponível. Pondera-se que os trabalhadores possuem direitos fundamentais expostos por meio das normas imperativas do Estado, em que o ente estatal é o verdadeiro sujeito passivo nas relações entre o direito subjetivo público e a prestação de caráter social. Assim, havendo inatividade do legislador com relação aos direitos laborais, ocorreria violação ao direito fundamental.

A flexibilização pressupõe a existência de intervenção estatal, respeitando-se os direitos fundamentais e verificando-se que a autonomia da vontade coletiva não poderá sobrepor os limites constitucionais, que são imodificáveis, e os princípios de Direito do Trabalho exercem importante papel na limitação da flexibilização.

\section{CONSIDERAÇÕES FINAIS}

Diante do exposto, apresentam-se as seguintes considerações acerca da flexibilização como fenômeno jurídico e sua relação com o contexto social vigente.

Nitidamente, relaciona-se o Direito do Trabalho e a crise econômica, impulsionada pelo fenômeno da globalização, de modo que, a partir da sua ocorrência, outros fenômenos secundários também se desencadearam, tais como a privatização e terceirização. $\mathrm{Na}$ globalização, é possível perceber que a ideia de unicidade e soberania do Estado é deixada de lado, embora seja respeitada. Todavia, as relações transbordam os limites e fronteiras físicas, visto que a livre circulação de capital é altamente difundida por toda a sociedade.

No que diz respeito ao impacto econômico, ela está associada a diversos fatores, tais como a revolução tecnológica, a adoção de políticas econômicas influenciadas pela ideologia neoliberal no mundo atual, grau de liberdade na movimentação do capital, ampliação do fluxo de comércio e informações, atuação das empresas transnacionais, dentre outros.

Da globalização, decorrem as políticas neoliberais, que se baseiam no conjunto de ideias políticas e econômicas advindas do capitalismo que defende a não participação do 
Estado na economia, havendo ampla liberdade do comércio, responsável por um determinado crescimento econômico.

Tendo em vista a existência dos aspectos mencionados, figura-se a denominada crise valorativa da legislação trabalhista. A norma laboral é apontada como causa de toda a crise econômica nas corporações, que, por sua vez, está associada à situação de conflito que impactam nas relações sociais e também na organização social, sendo meramente complexo atribuir a sua causa no contexto econômico, exclusivamente a positivação trabalhista.

O Direito do Trabalho é acusado pelo neoliberalismo por todos os males atuais na sociedade no que diz respeito aos problemas econômicos, de modo que o elevado índice de norma jurídica atrelada à responsabilização dos empregadores inibe a modernização do processo produtivo, assim como inibe os investimentos, sacrificando cada vez mais os desempregados e jovens que almejam recolocação ou colocação no mercado de trabalho.

Por outro lado, menciona-se que o Direito do Trabalho traz consigo importantes funções, como a promoção da justiça social, mesmo que de forma genérica, distribuindo aos trabalhadores determinados ganhos econômicos, eleva e moderniza a economia e a sociedade, bem como traz um ideal democrático e civilizatório.

Em relação à flexibilização do Direito do Trabalho, trata-se de um fenômeno que visa a ajustar e a afastar a rigidez das normas trabalhistas ante a globalização econômica e o neoliberalismo, justificando essa necessidade em decorrência das crises que assolam toda a sociedade, sendo uma alternativa de aumento da produtividade e também do lucro.

Fundamenta-se no sentido de que a legislação trabalhista deve se manter maleável em razão da rigidez legal dos direitos sociais, sendo uma reação aos padrões até então vigentes da legislação que estão em desacordo com a realidade.

A flexibilização contribui com a norma trabalhista, que deixa de ser rígida, adotando medidas e condições de trabalho menos favoráveis do que as previstas em lei, mediante uma negociação prévia ou coletiva, em que a perda de vantagens pode ser compensada pela inserção de outros benefícios de cunho social, por exemplo, mas que não onerará excessivamente a empresa, que, em via de regra, está em crise ou em transformação na sua realidade produtiva.

Os mecanismos de flexibilização são reais na Constituição Federal Brasileira, de modo que a Carta Magna Nacional iniciou um processo de modernização do Direito do Trabalho Brasileiro, visando a afastar a tutela do Estado e a abrir margens de entendimento 
entre empregados e empregadores. Dentre essas alterações, destacam-se a negociação coletiva e o acordo coletivo, tendo esses as funções de alterar em benefício ou não ao trabalhador.

Com isso, diante dos momentos de depressão econômica, a flexibilização, se respeitada os ditames legais, tais como os direitos fundamentais, não se trata de precarização, mas sim de adaptação do Direito do Trabalho na realidade social, visando, inclusive, a manutenção plena do emprego e de postos de trabalho.

\section{REFERÊNCIAS}

ANTUNES, Ricardo. O sentido do trabalho. São Paulo: Boitempo, 1999.

BARROS, Cássio Mesquita. Flexibilização do Direito do Trabalho e Terceirização. In: Revista dos Tribunais Caderno de Direito Tributário e Finanças Públicas. vol. 5, out/dez 1997.

BECK, Ulrich. ¿Qué es la globalización? Falacias del globalismo, repuestas a la globalización. Buenos Aires: Paidós, 2004.

CAMPANA, Priscila. O impacto do neoliberalismo no direito do trabalho: desregulamentação e retrocesso histórico. Revista de Informação Legislativa, Brasília/DF, v. 37, n.147, 2000.

CATHARINO, José Martins. Neoliberalismo e sequela: privatização, desregulação, flexibilização, terceirização. São Paulo: LTr, 1997.

CAVALCANTI, Lygia Maria de Godoy Batista. A flexibilização do Direito do Trabalho no Brasil: Desregulação ou Regulação Anética do Mercado?. São Paulo: LTr, 2008.

DEGENSZAJN, Raquel Raichelis. Proteção Social e Trabalho do Assistente Social: tendências e disputas na conjuntura de crise mundial. Serviço Social \& Sociedade, v. 116, p. 609-635, 2013.

DRUCKER, Peter. Sociedade pós-capitalismo. Coimbra: Conjuntura Actual Editora, 1993.

GENRO, Tarso Fernando. Crise da democracia: direito, democracia direta e neoliberalismo na ordem mundial. Petrópolis: Vozes, 2002.

GOLDSCHMIDT, Rodrigo. Flexibilização dos Direitos Trabalhistas. Ações afirmativas da dignidade da pessoa humana como forma de resistência. São Paulo: LTr, 2009.

HOYOS, Arturo. Estudios sobre flexibilidad en Panamá. Tradução: Sérgio Pinto Martins.

Revista de la Facultad de Ciencias Juridicas y Politicas, Caracas, n 75, 1990.

KREIN, José Dari. WEISHAUPT PRONI, Marcelo. Economia informal: aspectos conceituais e teóricos. Escritório da OIT no Brasil. - Brasília: OIT, 2010. 
LEITE, Jorge. Direito do trabalho na crise. In: Temas de Direito do Trabalho, Coimbra, 1990.

LUCA, Guilherme Domingos de; POZZOLI, L. A relação direito e fraternidade como instrumento promocional da dignidade da pessoa humana no direito do trabalho. In: CONPEDI; UFMG; FUMEC; Dom Helder Câmara. (Org.). Direito do trabalho e meio ambiente do trabalho I. 1ed. Belo Horizonte: , 2015, v. 1, p. 88-107.

MAGALHÃES, José Luis Quadros de. Direito constitucional. Belo Horizonte:

Mandamentos, v. 1, 2000.

MANUS, Pedro Paulo Teixeira. Direito do Trabalho. 7. ed. São Paulo: Atlas, 2002.

MARTINS FILHO, Ives Gandra da Silva. Manual esquemático de direito e processo do trabalho. 7. ed. São Paulo: Saraiva, 1998.

MARTINS, Sérgio Pinto. Flexibilização das condições de trabalho. 5. ed. São Paulo: Atlas, 2015.

NASCIMENTO, Amauri Mascaro. Limites da negociação coletiva na perspectiva do projeto de flexibilização da CLT. São Paulo: LTr, 2001.

NASSIF, Elaine Noronha. Fundamentos da flexibilização: uma análise de paradigmas e paradoxo do direito e do processo do trabalho. São Paulo: LTr, 2001.

ORGANIZAÇÃO DE COOPERAÇÃO E DE DESENVOLVIMENTO ECONÔMICO OCDE. Flexibilité dans la gestion du personnel de l'administration publique. Tradução: René Loncan Filho, 1986.

PASTORE, José. Flexibilização dos mercados de trabalho e contratação coletiva. São Paulo: LTr, 1995.

PILATI, José Isaac. Por um novo agora perante o desafio da globalização. Revista Jurídica, n. 19, jan./jun. Blumenau: Edifurb, 2006.

RIFKIN, Jeremy. O fim dos empregos: o declínio inevitável dos níveis dos empregos e a redução da força global de trabalho. Tradução: Ruth Gabriela Bahr. São Paulo: Makron Books, 1996.

SALAMA, Pierre. Pobreza e Exploração do Trabalho na América Latina. Tradução: Emir Sader. São Paulo: Boitempo, 1999.

SÁVIO, Luciane Alves. Flexibilização do direito do trabalho e implantação da autonomia privada coletiva no Brasil. In: DALLEGRAVE NETO, José Affonso (Coord.). Direito do trabalho: estudos. São Paulo: LTr, 1997.

SOUZA, Ney Lopes de. Flexibilização e Sindicalismo no Brasil. In: Fórum Internacional sobre flexibilização no Direito do Trabalho. Tribunal Superior do Trabalho (org.). Flexibilização no Direito do Trabalho. 2. ed. São Paulo: IOB Thomson, 2004. 
VIEIRA, Liszt. Cidadania e globalização. Rio de Janeiro: Record, 1998.

XAVIER, Bernardo da Gama Lobo. O direito do trabalho na crise. In: Temas de Direito do Trabalho, Coimbra, 1990. 